\title{
STRATEGIES FOR MINIMIZING INFORMATION ASYMMETRIES IN CONSTRUCTION PROJECTS: PROJECT MANAGERS' PERCEPTIONS
}

\author{
Anita Ceric \\ Department of Construction Management and Economics, Faculty of Civil Engineering \\ University of Zagreb, Kaciceva 26, 10000 Zagreb, Croatia \\ Email: anita@grad.hr
}

Received 18 June 2012; accepted 09 August 2012

\begin{abstract}
Communication risk is of crucial importance in construction projects. The situation in which one of the project parties is better informed than another is known as information asymmetry. This problem is addressed by the principal-agent theory. According to this theory, information asymmetries cause three problems: adverse selection, moral hazard, and hold up. The focus here is on strategies for minimizing information asymmetries in the construction phase. A survey of project managers was conducted to establish an understanding of the relative importance of risk-minimization strategies established in the literature: bureaucratic control (contracts), information systems, incentives (bonuses), corporate culture, reputation, and trust. The multi-attribute utility theory was used to analyze the responses. According to the project managers who participated in the survey, trust is the most important strategy in the construction phase, followed by bureaucratic control (contracts) and information systems.
\end{abstract}

Keywords: principal-agent theory, information asymmetries, risk-minimization strategies, project managers, trust, multi-attribute utility theory.

Reference to this paper should be made as follows: Ceric, A. 2014. Strategies for minimizing information asymmetries in construction projects: project managers' perceptions, Journal of Business Economics and Management 15(3): 424-440.

JEL Classification: D8, D82.

\section{Introduction}

The research presented here has evolved in three stages, of which the last one is presented in this paper. The results of previous stages were presented elsewhere (Ceric 2010, 2011, 2012). Throughout, the principal-agent theory has formed the foundation of the research project. The relationship between the project owner and contractor was extended to include their respective project managers. The project owner is the overall principal, and all the others are agents. However, the contractor is the principal with respect to the contractor's project manager. These four participants are crucial in every construction project. 
What makes this paper different from those published so far is that the focus here will be on communication issues between four parties involved in construction projects: project owner, contractor, and their project managers. In the literature we can find "classical" principal-agent theory applied to construction projects that discusses issues between the project owner and the project manager working on the project owner's behalf, as well as the contractor and the contractor's suppliers, but none have discussed the relationships and communication risks of all four parties mentioned above, who perforce play the most important role in every construction project.

The first stage of the research involved an exploratory survey of project managers with substantial experience in the field. The research considered all project phases, both before and after the contract is signed between the key project parties. It was established that the relationship between the two project managers is central to the construction phase itself, which is characterized by risk minimization. During this phase, the project owner and contractor play subsidiary roles, which offers an interesting challenge to the principal-agent theory because both project managers are agents, and there is no contract between them.

The second stage probed this finding by using the Delphi method. Again, a panel of highly-experienced project managers working for both project owners and contractors were asked several rounds of questions in an attempt to arrive to a consensus concerning the most important relationships between project parties in terms of risk minimization in the construction phase. The results obtained by the Delphi method confirmed the findings of the exploratory survey.

The third and final stage of the project involved another exploratory survey to establish the relative importance of different risk-minimization strategies in the construction phase. Project managers who participated in previous research stages were approached once again. Following the principal-agent theory, Schieg (2008) offered the following riskminimization strategies in construction projects: bureaucratic control (contracts), information systems, incentives (bonuses), corporate culture, reputation, and trust. It is hoped that the results presented below will be of help in guiding future research in this field.

This paper is presented in eight sections. First, the principal-agent theory as applied to construction is presented. Second, strategies for minimizing information asymmetries in construction projects are discussed. Third, the research methodology is presented. Fourth, the results from the survey questionnaire are examined. Fifth, comments by respondents are presented. Sixth, these results are combined with results of the previous research to arrive at the final ranking of risk-minimization strategies using multiattribute utility theory. Seventh, the limitations of the study are discussed. Finally, conclusions and suggestions for further research are presented.

\section{The principal-agent theory applied to construction projects}

Communication and exchange of information are of vital importance in all construction projects. According to Turner and Müller (2004), the key relationship is between the project owner as the principal and the contractor as an agent. As Ceric (2010) ar- 
gues, the project owner's and contractor's project managers also play important roles in construction projects as agents. Here, the contractor acts as the principal in relation to the contractor's project manager. According to the principal-agent theory, information asymmetries apply whenever the principal and the agent are not in possession of the same information at the same time. There are several types of information asymmetries: hidden characteristics, hidden information, and hidden intention. These three types of information asymmetries generate the following types of risk: adverse selection, moral hazard, and hold-up (Jäger 2008).

Adverse selection describes information asymmetries when the principal does not have the exact qualifications of the agent. It occurs before the contract between them is signed. The result can be the wrong choice of the contractual partner. In the case of the moral hazard there are information asymmetries after the contract is signed. The principal cannot control all the agent's activities and an information imbalance in favour of the agent can occur. If the agent uses this situation opportunistically, then this type of asymmetric information is called moral hazard. If the principal makes large investments in money or other resources because of the trusty relationship with the agent, and if these investments get lost in the case that the agent acts uncooperatively, these result with the problem called hold-up. The principal has already made an irreversible investment and this enables the agent to confront the principal with excessive demands, for instance.

The owner of a project is the person or group that provides the financial resources for its delivery, accepts the project milestones, and project completion (Project Management Institute 2000). In construction projects, the project owner hires a contractor to perform all the activities required to complete the project. Also, the project owner and the contractor delegate their tasks to their project managers. Therefore, there are four different parties involved in the project even before its execution starts. It should be noted that the contractor's project manager is understood here as the person who is in overall charge of a particular project on contractor's behalf irrespective of the title. In some business environments this role is played by consultants. However, it is important to note that project owner's and contractor's project managers play important roles in any construction project even though they are not in a contractual relationship with each other.

\section{Communication risk-minimization strategies}

The previous research has shown that project managers play the most important role in risk minimization in the construction phase, after the contract between the project owner and contractor is signed (Ceric 2010, 2011). Therefore, the research presented here is focused on the construction phase and communication risk minimization in this phase. According to Schieg (2008), there are six strategies for minimizing information asymmetries between project participants: bureaucratic control (contracts), information systems, incentives (bonuses), corporate culture, reputation and trust.

The above strategies find considerable albeit fragmentary support in the literature. They will be considered in turn. The relationship between project participants is generally 
controlled by means of contract (Bower, Skountzos 2003). The contract sets out the intentions of the two parties, and so the roles and responsibilities of both sides are clear in the case any dispute arises (Simester, Turner 2003).

As Schieg (2008) points out, information systems promote transparency, directness, and timeliness of communication, as well as permanence of the information available. Current emphasis is firmly on digital information and improved communication through web technologies that provide tools for better exchange of information between project participants (Emmitt, Gorse 2007).

The use of incentives involves payment of a bonus or incentive to a contract party for performing its work (Bower, Skountzos 2003). In partnering, incentives are an important way of reinforcing collaboration in the short term and helping to build trust between project participants (Bresnen, Marshall 2000).

According to Schieg (2008), corporate culture plays a special role in construction. Shared values, targets, and competences minimize coordination costs. Also, it gives identity to an organization (Cheung et al. 2011).

Reputation is a key component of strategic competitive advantage (Jäger 2008). As such, it is capable of effectively countering harmful opportunistic behavior. However, it should be noted that reputation has relevance only with respect to past action (Wilson 1985).

According to Zaghloul and Hartman (2003), the success of any construction project is questinable without trust even when powerful control systems, including contractual documents, are available. As Kadefors (2004) argues, if trust is present, people can spontaneously engage in constructive interaction without pondering what hidden objectives motivate their partners.

Grounded in large part in the principal-agent theory, the above strategies offer a coherent framework for further investigation. It is hoped that the results of the research presented here will be of value in further inquiry. However, risk-minimization strategies certainly need greater emphasis in future research.

\section{Research methodology}

As stated in the Introduction, the research presented here is the third and final stage of an investigation into project managers' perceptions concerning communication risk due to asymmetric information in construction projects. Throughout, the principal-agent theory has provided the foundation for the investigation.

The same twenty respondents who participated in the previous stages of this research were selected for the present stage. The previous stage employed the Delphi method. The respondents are practitioners with considerable expertise in the field as witnessed by their thirteen years of experience on the average and the average value of the largest project they have managed assessed at $\$ 1.4$ billion. They have worked both for project owners and contractors in more than thirty countries, including Egypt, Hong Kong, India, Iraq, Italy, Pakistan, Poland, Russia, Saudi Arabia, Spain, Switzerland, Turkey, 
the United Kingdom, and the United States. Many of the largest projects have been in infrastructure, but many other types of projects were involved. However, the respondents cannot be said to be representative of all project managers, the population of which is beyond the scope of the present study.

At this stage of the research project, the respondents were asked to rank the risk-minimization strategies presented above in terms of their importance in reducing information asymmetry (Appendix). The scale used was from 1 to 9 , where 9 is "most important." This scale is ostensibly ordinal, but it can be meaningfully interpreted as the interval scale, as it involves only levels of importance, from least to most important. Each level of importance can be understood as the same as any other, and the scale can thus be interpreted as linear.

As will be shown below, the means and standard deviations of the answers are presented first. Then the utility functions are calculated using the multi-attribute utility theory. These functions are calculated by combining the relative importance of strategies in the focus at this stage of the research, and the relative importance of different relationships between project parties, which were obtained in the Third Delphi Round at the previous stage of the research (Ceric 2011). The overall utility function that ranks all the strategies was thereby obtained.

The multi-attribute utility theory is a well-known decision-making technique used under conditions of both certainty and uncertainty (Luce, Raiffa 1957; Kenney, Raiffa 1976; Saaty 1994; Flanagan, Norman 1993; Ceric 2003). It is used in cases when the best alternative solution must be chosen, i.e. for compiling a ranking list of the alternatives offered. Here, the alternatives are the risk-minimization strategies. Alternatives are weighted with respect to one or more given criteria with the purpose of calculating the overall utility function for each alternative. Here, the criteria are the relationships between project parties. Multi attribute utility theory takes into consideration the decisionmaker's preferences in the form of the overall utility function which is defined over a set of criteria. The value of the overall utility function is used to form the ranking list of alternatives - that is, to provide the best alternative.

The overall utility function values for each alternative can be obtained by the following equations:

$$
\begin{gathered}
U\left(S_{j}\right)=\sum_{i=1}^{n} w_{i} \overline{U_{i}}\left(S_{j}\right), \quad j=1,2, \ldots, m, \\
w_{i}=\frac{R_{i}}{\sum_{k=1}^{n} R_{k}}, \quad i=1,2, \ldots, n, \\
\overline{U_{i}}\left(S_{j}\right)=\frac{U_{i}\left(S_{j}\right)}{\sum_{k=1}^{m} U_{i}\left(S_{k}\right)}, \quad i=1,2, \ldots, n ; j=1,2, \ldots, m, \\
\sum_{j=1}^{m} U\left(S_{j}\right)=1,
\end{gathered}
$$




$$
\begin{gathered}
\sum_{i=1}^{n} w_{i}=1, \\
\sum_{i=1}^{n} \overline{U_{i}}\left(S_{j}\right)=1, \quad i=1,2, \ldots, n,
\end{gathered}
$$

where: $S_{j}$ - risk-minimization strategy $j, R_{i}$ - relationship $i$ between project parties, $m$ - number of strategies, $n$ - number of relationships, $w_{i}$ - weight of importance for relationship $i, U\left(S_{j}\right)$ - overall utility function value for strategy $j, U_{i}\left(S_{j}\right)$ - utility function value for relationship $i$ and strategy $j, \overline{U_{i}}\left(S_{j}\right)$ - normalized utility function value for relationship $i$ and strategy $j$.

The multi attribute utility theory is part of multi-criteria decision analysis which has been widely used in construction industry. Different multi-criteria methods are used for multi-objective optimization of multi-alternative decisions in road construction (Brauer et al. 2008), assessment of quality in bridges and road construction (Zavadskas et al. 2008a), contractor selection of construction in a competitive environment (Zavadskas et al. 2008b), evaluation of the alternative solutions of wall insulation (Ginevicius et al. 2008), realization of construction projects (Sarka et al. 2008), decision making in construction design and management (Turskis et al. 2009), selection of concrete pumps (Ulubeyli, Kazaz 2009), reuse selection of historic buildings (Wang, Zeng 2010), planning urban infrastructures (Coutinho-Rodrigues et al. 2011), life costing design (Wang 2011), construction and demolition waste management (Xanthopoulos et al. 2012) and sustainable performance of a building envelope for an energy efficient design (Mwasha et al. 2012).

Multi-attribute utility theory was used for risk assesment in construction (Zavadskas et al. 2008c), selecting a dismantling scenario (Kim, Song 2009), decision making in project management (Marques et al. 2010) selection of contruction method in concrete buildings (Chen et al. (2010), bridge management (Dabous, Alkass 2010), contractor selection innovation (Holt 2010), choosing an appropriate project delivery system (Ibbs, Chih 2011), system selection in environmentally friendly drilling (Yu et al. 2011), impact on environment of underground infrastructure work (Zayed et al. 2011) and selection of engineered equipment suppliers (Azambuja, O’Brien 2012).

\section{Survey questionnaire results}

Out of twenty respondents who received the exploratory survey, fifteen have responded (response rate: 75 percent). Again, the respondents have participated in the previous two stages of this research project (Ceric 2010, 2011). All the respondents are project managers with extensive international experience, who have worked for both project owners and contractors. The results of the survey concerning risk-minimization strategies in the construction phase are presented in the form of mean values and standard deviations (Table 1). These results will be further refined below using the multi-attribute utility theory, but several brief comments are in order at this stage.

As can be seen from Table 1, the most important risk-minimization strategy in the relationship between the project owner and contractor in the construction phase is bureau- 
cratic control (contracts). In addition to the highest mean value, the standard deviation is lowest, showing agreement between respondents. This shows that the respondents are in agreement as to the importance of this strategy even in the construction phase. However, trust comes on top in terms of importance in all other relationships covered by the survey. Most important, trust is the key to the relationship between the project managers and their employers - the project owner and contractor. This is shown not only by the highest mean values, but also by the lowest standard deviations. This is an important result of potential value for future research.

Table 1. Results of the survey questionnaire

\begin{tabular}{|c|c|c|c|c|c|}
\hline \multicolumn{2}{|l|}{ Strategies/Relationships } & 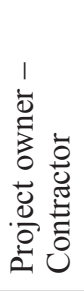 & 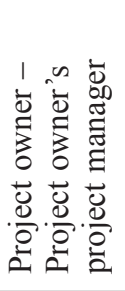 & 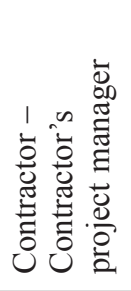 & 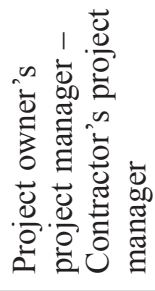 \\
\hline \multirow[t]{2}{*}{ Bureaucratic control (contracts) } & Mean & 8.40 & 5.93 & 5.47 & 6.73 \\
\hline & St. Dev. & 1.12 & 2.34 & 2.03 & 2.49 \\
\hline \multirow[t]{2}{*}{ Information systems } & Mean & 5.60 & 6.73 & 6.47 & 6.80 \\
\hline & St. Dev. & 2.10 & 1.91 & 2.13 & 2.21 \\
\hline \multirow[t]{2}{*}{ Incentives (bonuses) } & Mean & 5.40 & 6.00 & 6.00 & 3.60 \\
\hline & St. Dev. & 2.50 & 1.96 & 2.17 & 2.38 \\
\hline \multirow[t]{2}{*}{ Corporate culture } & Mean & 5.27 & 6.33 & 6.40 & 5.47 \\
\hline & St. Dev. & 2.02 & 1.59 & 1.35 & 2.23 \\
\hline \multirow[t]{2}{*}{ Reputation } & Mean & 6.80 & 6.40 & 5.87 & 5.80 \\
\hline & St. Dev. & 1.66 & 1.40 & 1.88 & 2.31 \\
\hline \multirow[t]{2}{*}{ Trust } & Mean & 6.20 & 8.40 & 8.27 & 7.47 \\
\hline & St. Dev. & 2.18 & 0.83 & 0.96 & 1.77 \\
\hline
\end{tabular}

\section{Project managers' perceptions of risk-minimization strategies}

In support of the main findings, it is useful to review the respondents' comments in to the last part of the survey. In particular, the respondents were asked to comment on the strategy/relationship they considered most important. Here, only a selection of these comments will be presented.

Most important, the respondents recognize the key place of the contract in construction projects. However, they also believe that trust is crucial to the success of these projects. One respondent states as follows: "Contract is the most important instrument that regulates the information between the project owner and contractor. Hence, a well-designed contract which describes the ways of information transfer is the most effective way to 
decrease the information asymmetry risk. On the other hand, regarding the parties and their project managers, trust is an important issue affecting the information transfer. A trustful relation between the project owner and the owner' project manager and the contractor and the contractor' project manager can prevent conflict of interests between the parties and it can promote the information exchange."

Another respondent argues in a similar vein: "Bureaucratic and other pre-defined formal-control methods are the most effective means at corporate level (i.e. between the companies). However, less formal control methods come into the picture at the personal level and between the companies and their managers. In conclusion, it is always the contract between the project owner and the contractor used by all parties that is at issue when problematic conditions arise during construction. A well-defined contract is the most important mean to reduce risks to the minimum."

Yet another respondent states as follows: "Trust takes time to develop between the parties, and it is very fragile, but once developed it outshines all the other strategies in terms of project control and risk minimization." Similarly, another respondent argues: "The most important document is the contract. But the trust between the parties is as important as the contract." With respect to the relationship between the contractor and the contractor's project manager, one respondent states as follows: "Contractor should entrust an assignment to his project manager with full trust that he can competently perform. However, the contractor's trust should be reflected in the service contract, giving the project manager a mandate sufficient for implementation of the risk-minimization policies."

One respondent comments on information systems as a strategy in the following words: "Project managers need to set up as good information systems as possible to keep all moves visible to all parties at all times. Last but not least, such visibility leads to stability and trust in the project."

Concerning reputation as a strategy, one respondent states as follows: "Reputation is the most important strategy since a contractor with good reputation to complete the project on time and with minimum problems will definitely minimize the risk for the project owner. It is the same for the contractor. A reputable project manager will definitely be much more predictable for the employers than any other. So the risk is minimized."

One of the responses concerning incentives is as follows: "Incentives are important for the stakeholders executing the project. One of the problems is that the incentives between the different stakeholders (basically the project owner and contractor) might not be aligned, thus leading to inefficiencies in the whole process. My guess is that the alignment of all the incentives, plus a robust performance management structure to keep track of these incentives, could improve the project performance substantially. The alternative is to control the performance and/or risk of the contractor by using bureaucratic control, which might be less constructive and might lead to operational inefficiencies."

Overall, bureaucratic control (contracts) is given an important place in most comments by respondents, but trust nonetheless surfaces as the most important risk-minimization 
strategy in the construction phase. This is reflected in the numerical results presented in Table 1. Information systems, reputation, and incentives are commented upon by several respondents only. Interestingly, no respondent has commented on corporate culture as a strategy.

\section{Ranking of risk-minimization strategies using multi-attribute utility theory}

The multi-attribute utility theory was used for the calculation of the overall utility functions used to define the ranking of strategies for minimization of risks caused by information asymmetries in the construction phase offered by Schieg (2008). The overall utility function combines the weights of importance of relationships between project parties and the ranking of risk-minimization strategies. The calculation of the overall utility function to arrive at the final ranking proceeded in three steps.

First, the results of Delphi Round Three from Ceric (2011) were used for the determination of weights of importance $\left(w_{i}\right)$ for each relationship between the four $(n)$ key participants. For the calculation, mean values of project managers' responses were used (Table 2). They range from 1 to 9 in terms of importance. In Delphi Round Three, each relationship was considered from both sides, as indicated by arrows in the table. The mean values of these are used at this stage. The results are presented in Figure 1.

Table 2. Results of Delphi Round Three (Ceric 2011)

\begin{tabular}{clcc}
\hline Rank & \multicolumn{1}{c}{ Relationship } & Mean & St. Dev. \\
\hline 1 & Project owner's project manager $\rightarrow$ Contractor's project manager & 8.57 & 0.65 \\
\hline 2 & Contractor's project manager $\rightarrow$ Project owner's project manager & 8.46 & 0.63 \\
\hline 3 & Project owner $\rightarrow$ Project owner's project manager & 7.07 & 1.07 \\
\hline 4 & Project owner $\rightarrow$ Contractor & 6.79 & 0.97 \\
\hline 5 & Contractor $\rightarrow$ Project owner & 6.71 & 0.99 \\
\hline 6 & Project owner's project manager $\rightarrow$ Project owner & 6.61 & 1.18 \\
\hline 7 & Contractor $\rightarrow$ Contractor's project manager & 6.57 & 1.16 \\
\hline 8 & Contractor's project manager $\rightarrow$ Contractor & 6.36 & 1.15 \\
\hline
\end{tabular}

For the calculation of the weight of importance concerning relationships between project parties for minimizing the risks caused by information asymmetries, averages of mean values of project managers' responses from both sides are used:

$R_{1}$ - Project owner - Contractor: $(6.79+6.71) / 2=6.75$,

$R_{2}$ - Project owner - Project owner's project manager: $(7.07+6.61) / 2=6.84$,

$R_{3}$ - Contractor - Contractor's project manager: $(6.57+6.32) / 2=6.47$,

$R_{4}$ - Project owner's project manager - Contractor's project manager:

$(8.57+8.46) / 2=8.52$. 


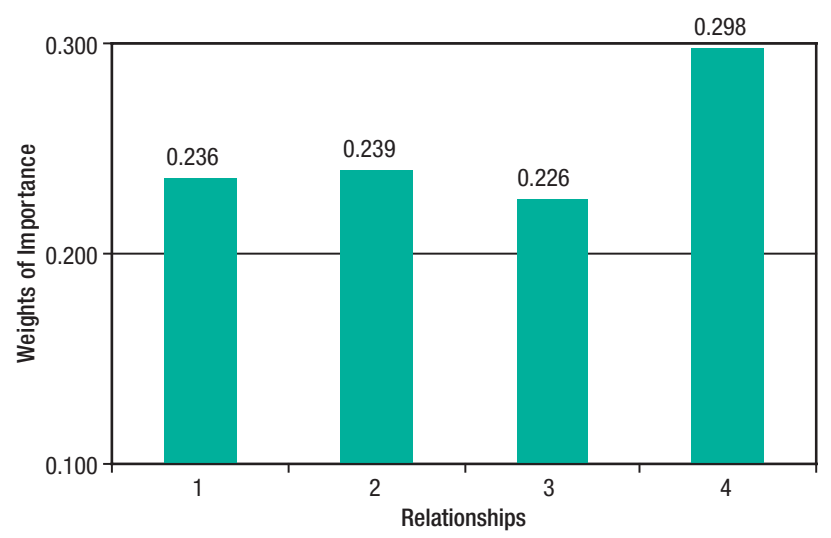

Fig. 1. Utility function values for relationships between key project parties: 1) Project owner Contractor; 2) Project owner - Project owner's project manager; 3) Contractor - Contractor's project manager; and 4) Project owner's project manager - Contractor's project manager

Subsequently, the average values are added, and the weights of importance are obtained by means of normalization using equation (2). For example (7), the weight of importance for the relationship between the project owner and contractor for minimizing the risks caused by information asymmetries is calculated as follows:

$$
w_{1}=\frac{R_{1}}{\sum_{i=1}^{4} R_{i}}=\frac{6.75}{6.75+6.84+9.47+8.52}=0.236 .
$$

The sum of all weights of importance concerning relationships between project parties for minimizing the risks caused by information asymmetries (8) according to equation (5) equals 1 :

$$
\sum_{i=1}^{n} w_{i}=0.236+0.239+0.226+0.298=1 \text {. }
$$

Second, the utility function values for four $(n)$ relationships and six $(m)$ strategies $\left(U_{i}\left(S_{j}\right)\right)$ are obtained from the responses of project managers (Table 1). Again, the scale from 1 to 9 in terms of importance was used (Appendix). These are the alternatives for risk minimization in the construction phase. For the calculation of normalized utility functions $\left(\overline{U_{i}}\left(S_{j}\right)\right)$ using equation (3), mean values from the responses of project managers are used once again (Table 3 ).

For example (9), the normalized utility function value for the relationship (1) between the project owner and contractor and strategy (1) bureaucratic control including contracts is calculated as follows:

$$
\overline{U_{1}}\left(S_{1}\right)=\frac{U_{1}\left(S_{1}\right)}{U_{1}\left(S_{1}\right) \sum_{k=1}^{6} U_{1}\left(S_{k}\right)}=\frac{8.40}{8.40+5.60+5.40+5.27+6.80+6.20}=0.223 .
$$


Table 3. Utility function values for risk-minimization strategies

\begin{tabular}{|c|c|c|c|c|}
\hline Strategies/Relationships & 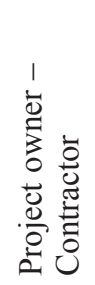 & 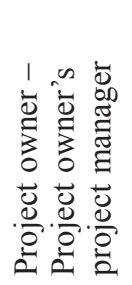 & 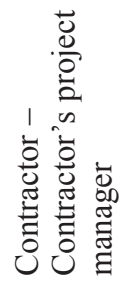 & 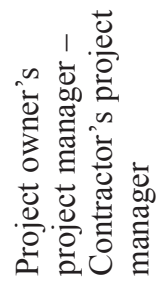 \\
\hline Bureaucratic control (contracts) & 0.223 & 0.149 & 0.142 & 0.188 \\
\hline Information systems & 0.149 & 0.169 & 0.168 & 0.190 \\
\hline Incentives (bonuses) & 0.143 & 0.151 & 0.156 & 0.100 \\
\hline Corporate culture & 0.140 & 0.159 & 0.166 & 0.152 \\
\hline Reputation & 0.181 & 0.161 & 0.153 & 0.162 \\
\hline Trust & 0.165 & 0.211 & 0.215 & 0.208 \\
\hline
\end{tabular}

The sum of all normalized utility function values concerning relationship between the project parties and six risk-minimization strategies (10), according to equation (6) equals 1:

$$
\sum_{i=1}^{n} \overline{U_{i}}\left(S_{1}\right)=0.223+0.149+0.142+0.188+0.180+0.165=1 .
$$

Third, the overall utility function values $U\left(S_{j}\right)$ are calculated by combining four weights of importance concerning relationships between project parties and the utility functions for the four relationships between key parties and the six strategies using equation (1) (Fig. 2). The overall utility function values offers the ranking of riskminimization strategies in the construction phase. For example (11), it is calculated for strategy (1) bureaucratic control including contracts as follows:

$U\left(S_{1}\right)=\sum_{i=1}^{4} w_{i} \overline{U_{i}}\left(S_{1}\right)=0.236 \cdot 0.223+0.239 \cdot 0.149+0.226 \cdot 0.142+0.298 \cdot 0.188=0.176$.

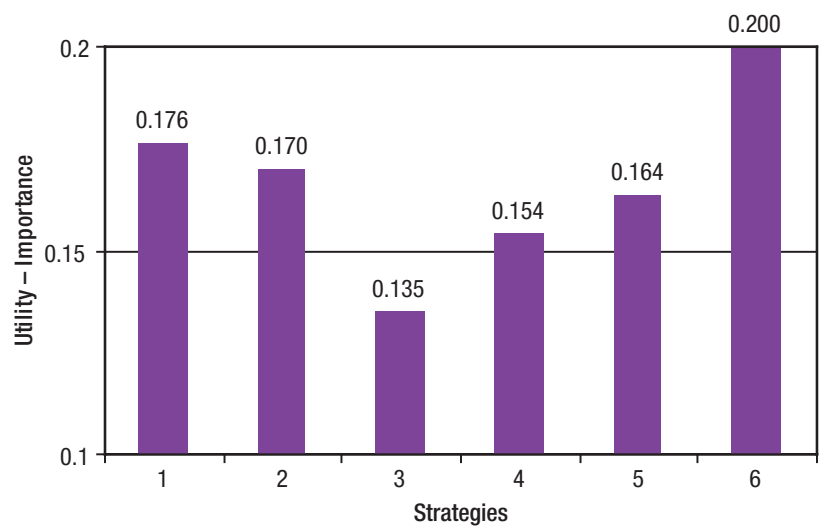

Fig. 2. Overall utility function values for risk-minimization strategies: 1) Bureaucratic control (contracts); 2) Information Systems; 3) Incentives (bonuses); 4) Corporate culture; 
The sum of all overall utility function values concerning all six strategies for minimizing the risks caused by information asymmetries (12), according to equation (6) equals 1 :

$$
\sum_{j=1}^{6} U\left(S_{j}\right)=0.176+0.170+0.135+0.154+0.165+0.200=1
$$

As Figure 2 shows, the multi-attribute utility theory applied in this research demonstrates that trust is the most important risk-minimization strategy in the construction phase. It is followed by bureaucratic control (contracts) and information systems. Reputation, corporate culture, and incentives (bonuses) follow, in that order. These results take into consideration both the relative importance of relationships between project parties, as presented in previous research (Ceric 2011), and the relative importance of strategies investigated at this stage.

\section{Limitations}

The main limitation of the results presented here is in the small number of respondents. Again, fifteen out of twenty respondents actually returned their responses. However, this limitation has to do with the Delphi method used in the previous stage of this research project. There, twenty potential respondents was an adequate number. Given their experience with the research presented here, which proceeded in three stages, it was considered worthwhile to gather their responses on risk-minimization strategies, as well.

\section{Conclusions}

The project managers play the most important role in risk minimization in the construction phase, after the contract is signed between the project owner and the contractor. The research presented here is focused on the construction phase and communication risk minimization in this phase. According to the literature, there are six strategies for minimizing information asymmetries between project participants: bureaucratic control (contracts), information systems, incentives (bonuses), corporate culture and trust. The survey of project mangers and its analysis using multi-attribute utility theory were employed to define the ranking of strategies for minimization of risks caused by information asymmetries.

The research presented in this paper shows that trust is the most important risk-minimization strategy in the construction phase. It is followed by bureaucratic control (contracts) and information systems. Reputation, corporate culture, and incentives (bonuses) follow, in that order. The importance of trust is a pointer for future research in project management. Although it is an elusive concept at first sight, practitioners in the field appreciate and understand it well.

There are three plausible directions for future research of risk minimization based on the principal-agent theory that are worth considering at this stage. First, strategies of communication risk minimization could be explored. The first step in this direction has been attempted in the research presented in this paper. Here, trust has emerged as the key strategy worthy of further investigation. Second, future research could look 
into more complex relationships between project participants, including the designer. Third, the communication process between project participants could be investigated in greater detail, so as to explore viable communication protocols between the key project participants.

\section{Acknowledgements}

I would like to thank two anonymous referees for their helpful comments. Also, I very much appreciate the contribution of the respondents of the survey: Serap Ciliz, Mete Demir, Ahmet Erol, Medhat Etman, Cihat Gurel, Sinisa Matic, Ferit Oncel Mocan, Sinisa Radakovic, Wilhelm Reismann, Ophir Rozenfeld, David Owen, Aydin Sakin, Gullem Sivecas Gibert, Rifat Sonmez, and Ertugrul Unluturk. I would like to thank them all. Last but not least, I would like to thank the Ministry of Science of the Republic of Croatia for the sponsorship of the five-year research project under my supervision entitled "Human resource management in construction projects" (Project Code Number: 082-0822156-2998).

\section{References}

Azambuja, M. M.; O’Brien, W. J. 2012. Rapid assessment and selection of engineered equipment suppliers, Automation in Construction 22: 587-596.

http://dx.doi.org/10.1016/j.autcon.2011.12.004

Brauers, W. K. M.; Zavadskas, E. K.; Peldschus, F.; Turskis, Z. 2008. Multi-objective decisionmaking for road design, Transport 23(3): 183-193.

http://dx.doi.org/10.3846/1648-4142.2008.23.183-193

Bower, D.; Skountzos, F. 2003. Partnering, benchmarking and incentive contracts, in Turner, R. (Ed.). Contracting for project management. Hampshire: Gower Publishing Limited: 81-104.

Bresnen, M.; Marshall, N. 2000. Motivation, commitment and the use of incentives in partnerships and alliances, Construction Management and Economics 18: 587-598.

http://dx.doi.org/10.1080/014461900407392

Ceric, A. 2003. A framework for process-driven risk management in construction projects. $\mathrm{PhD}$ Thesis, Research Institute for the Built \& Human Environment, School of Construction and Property Management, University of Salford, Salford.

Ceric, A. 2010. The impact of asymmetric information on communication in construction projects, in Engineering Projects Organizations Conference: Working Paper Proceedings, 4-7 November, 2010, South Lake Tahoe, California.

Ceric, A. 2011. Minimizing communication risk in construction projects: a Delphi study of the key role of projects managers, in Engineering Projects Organizations Conference: Working Paper Proceedings, 9-11 August, 2011, Estes Park, Colorado.

Ceric, A. 2012. The principal-agent theory and the role of project managers in construction: guidelines for future research, in CIB Proceedings, Management of Construction: Research to Practice, 26-29 June, 2012, Montreal, Canada.

Chen, Y.; Okudan, G. E.; Riley, D. R. 2010. Decision support for construction method selection in concrete buildings: prefabrication adoption and optimization, Automation in Construction 19(6): 665-675. http://dx.doi.org/10.1016/j.autcon.2010.02.011

Cheung, S. O.; Wong, P. S. P.; Wu, A. W. Y. 2011. Towards an organizational culture framework in construction, International Journal of Project Management 29: 33-44.

http://dx.doi.org/10.1016/j.ijproman.2010.01.014 
Coutinho-Rodrigues, J.; Simão, A.; Antunes, C. H. 2011. A GIS-based multicriteria spatial decision support system for planning urban infrastructures, Decision Support Systems 51(3): 720-726.

Dabous, S. A.; Alkass, S. 2010. A multi-attribute ranking method for bridge management, Engineering, Construction and Architectural Management 17(3): 282-291.

http://dx.doi.org/10.1016/j.dss.2011.02.010

Emmitt, S.; Gorse, C. 2007. Communication in construction teams. Oxon: Taylor and Francis.

Flanagan, R.; Norman, G. 1993. Risk management and construction. Oxford: Blackwell Science.

Ginevicius, R.; Podvezko, V.; Raslanas, S. 2008. Evaluating the alternative solutions of wall insulation by multicriteria methods, Journal of Civil Engineering and Management 14(4): 217-226. http://dx.doi.org/10.3846/1392-3730.2008.14.20

Holt, G. 2010. Contractor selection innovation: examination of two decade' published research, Construction Innovation: Information, Process, Management 10(3): 304-328.

Ibbs, W.; Chih, Y.Y. 2011. Alternative methods for choosing an appropriate project delivery system (PDS), Facilities 29(13/14): 527-541. http://dx.doi.org/10.1108/02632771111178418

Jäger, C. 2008. The principal-agent theory within the context of economic sciences. Norderstadt, Herstellung und Verlag, Books on Demand GmbH.

Kadefors, A. 2004. Trust in project relationship-inside the black box, International Journal of Project Management 22: 175-182. http://dx.doi.org/10.1016/S0263-7863(03)00031-0

Kenney, R. L.; Raiffa, H. 1976. Decisions with multiple objectives: preference and value tradeoffs. New York: John Willey and Sons.

Kim, S. K.; Song, O. 2009. A MAUT approach for selecting a dismantling scenario for the thermal column in KRR-1, Annals of Nuclear Energy 36(2): 145-150.

http://dx.doi.org/10.1016/j.anucene.2008.11.034

Luce, R. D.; Raiffa, H. 1957. Games and decisions. New York, John Willey and Sons.

Marques, G.; Gourc, D.; Lauras, M. 2010. Multi-criteria performance analysis for decision making in project management, International Journal of Project Management 29: 1057-1069.

http://dx.doi.org/10.1016/j.ijproman.2010.10.002

Mwasha, A.; Williams, R.G.; Iwaro, J. 2012. Approach for modelling the sustainable performance of a building envelope for an energy efficient design, International Journal of Multicriteria Decision Making 2(1): 47-73. http://dx.doi.org/10.1504/IJMCDM.2012.045082

Project Management Institute 2000. A guide to the project management body of knowledge. Newton Square, Pennsylvania.

Saaty, T. L. 1994. Fundamentals of decision making and priority theory with the analytic hierarchy process, Vol. 5, AHP Series. Pittsburgh, Pennsylvania: RWS Publications.

Sarka, V.; Zavadskas, E. K.; Ustinovicius, L.; Sarkiene, E.; Ignatavicius, C. 2008. System of project multicriteria decision synthesis in construction, Technological and Economic Development of Economy 14(4): 546-565. http://dx.doi.org/10.3846/1392-8619.2008.14.546-565

Schieg, M. 2008. Strategies for avoiding asymmetric information in construction project management, Journal of Business Economics and Management 9(1): 47-51.

http://dx.doi.org/10.3846/1611-1699.2008.9.47-51

Simister, S.; Turner, R. 2003. Standard form of contract, in R. Turner (Ed.). Contracting for project management. Hampshire: Gower Publishing Limited, 59-63.

Turner, R.; Müller, R. 2004. Communication and co-operation on projects between the project owner as principal and the project manager as agent, European Management Journal 22(3): 327-336. http://dx.doi.org/10.1016/j.emj.2004.04.010 
Turskis, Z.; Zavadskas, E. K.; Peldschus, F. 2009. Multi-criteria optimization system for decision making in construction design and management, Inzinerine Ekonomika - Engineering Economics (1): 7-17.

Ulubeyli, S.; Kazaz, A. 2009. A multiple criteria decision-making approach to the selection of concrete pumps, Journal of Civil Engineering and Management 15(4): 369-376.

http://dx.doi.org/10.3846/1392-3730.2009.15.369-376

Wang, N. 2011. Multi-criteria decision-making model for whole life costing design, Structure and Infrastructure Engineering: Maintenance, Management, Life-Cycle Design and Performance 7(6): 441-452. http://dx.doi.org/10.1080/15732470802670875

Wang, H. J.; Zeng, Z. T. 2010. A multi-objective decision-making process for reuse selection of historic buildings, Expert Systems with Applications 37(2): 1241-1249.

http://dx.doi.org/10.1016/j.eswa.2009.06.034

Wilson, R. B. 1985. Reputation in games and markets, in A. Roth (Ed.). Game theoretic models for bargaining with incomplete information. Cambridge: Cambridge University Press, 27-62. http://dx.doi.org/10.1017/CBO9780511528309.004

Xanthopoulos, A.; Aidonis, D.; Vlachos, D.; Iakovou, E. 2012. A planning optimisation framework for construction and demolition waste management, International Journal of Industrial and Systems Engineering 10(3): 257-276. http://dx.doi.org/10.1504/IJISE.2012.045675

Yu, O. Y.; Guikema, S. D.; Briaud, J. L.; Burnett, D. 2011. Quantitative decision tools for system selection in environmentally friendly drilling, Civil Engineering and Environmental Systems 28(3): 185-208. http://dx.doi.org/10.1080/10286608.2010.543280

Zaghloul, R.; Hartman, F. 2003. Construction contracts: the cost of mistrust, International Journal of Project Management 21: 419-424. http://dx.doi.org/10.1016/S0263-7863(02)00082-0

Zayed, T.; Salman, A.; Basha, I. 2011. The impact on environment of underground infrastructure utility work, Structure and Infrastructure Engineering: Maintenance, Management, Life-Cycle Design and Performance 7(3): 199-210. http://dx.doi.org/10.1080/15732470802445310

Zavadskas, E. K.; Liias, R.; Turskis, Z. 2008a. Multi-attribute decision-making methods for assessment of quality in bridges and road construction: State-Of-The-Art surveys, The Baltic Journal of Road and Bridge Engineering 3(3): 152-160.

http://dx.doi.org/10.3846/1822-427X.2008.3.152-160

Zavadskas, E. K.; Turskis, Z.; Tamosaitiene, J. 2008b. Contractor selection of construction in a competitive environment, Journal of Business Economics and Management 9(3): 181-187. http:// dx.doi.org/10.3846/1611-1699.2008.9.181-187

Zavadskas, E. K.; Turskis, Z.; Tamosaitiene, J. 2008c. Construction risk assessment of small scale objects by applying TOPSIS method with attributes values determined at intervals, Computer Modelling and New Technologies 12(4): 38-43.

\section{APPENDIX}

\section{Survey questionnaire}

The aim of this survey is to rank strategies for communication-risk minimization in the construction phase after the contract is signed between the project owner and contractor. There are four key parties crucial to the success of every project, and there are some risks associated with information asymmetry between them. In addition to the project owner and contractor, their project managers play key roles, as well. 
The construction literature offers the following six strategies for the minimization of risk caused by information asymmetry:

- bureaucratic control (contracts),

- information systems,

- incentives (bonuses),

- corporate culture,

- reputation,

- and trust.

In this survey, the task is to rank them in terms of each relationship involved. Here, we take each relationship to go both ways. The table below matches six strategies and four relationships. Each relationship should be considered in turn. For instance, start with the project owner and contractor by ranking all the strategies from 1 to 9 , and then proceed to the next relationship.

\section{Survey questions}

\section{A. General information}

Note that personal information will remain private.

Name:

B. Strategies for risk minimization - Relative importance of relationships between project parties

Please use the scale from 1 to 9 (where 9 is "most important") to rate the importance of each relationship between project parties in terms of strategies for risk minimization:

\begin{tabular}{|c|c|c|c|c|}
\hline Strategies/Relationships & 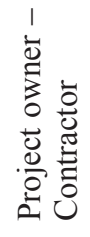 & 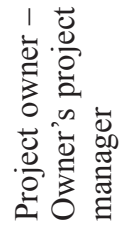 & 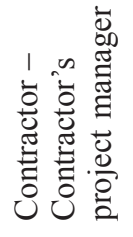 & 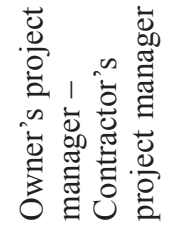 \\
\hline \multicolumn{5}{|l|}{ Bureaucratic control (contracts) } \\
\hline \multicolumn{5}{|l|}{ Information systems } \\
\hline \multicolumn{5}{|l|}{ Incentives (bonuses) } \\
\hline \multicolumn{5}{|l|}{ Corporate culture } \\
\hline \multicolumn{5}{|l|}{ Reputation } \\
\hline Trust & & & & \\
\hline
\end{tabular}

Please comment on the strategy/relationship in the above table that you consider most important. 
Anita CERIC is a Professor at the Department of Construction Management and Economics at the Faculty of Civil Engineering at the University of Zagreb. She was awarded her M.Sc. in Civil Engineering at the same University and she received her Ph.D. from the School of Construction and Property Management at the University of Salford, United Kingdom. Since 1995 she has been working at the Department of Construction Management and Economics, Faculty of Civil Engineering, at the University of Zagreb. Her research interests are in risk management, human resource management, and maintenance management. She is a member of editorial boards of four international journals. She is a member of W55 Working Commission on Building Economics and W65 Working Commission on Construction Management of the International Building Council (CIB); International Project Management Association (IPMA); Engineering Project Organizations Society (EPOS); and Academy of Management (AOM).. Currently, she is the Vice-Dean for International Collaboration at the Faculty of Civil Engineering at the University of Zagreb. Also, she is serving as the Head of the Laboratory of Information Technology at the Department of Construction Management and Economics of the same Faculty. 